\title{
A case of suicide by ingestion of caffeine
}

\author{
Alessandro Bonsignore - Sara Sblano • Fulvia Pozzi • \\ Francesco Ventura • Alessandro Dell'Erba • \\ Cristian Palmiere
}

Accepted: 9 April 2014/Published online: 27 April 2014

(C) Springer Science+Business Media New York 2014

\begin{abstract}
Intentional or unintentional caffeine abuse due to excessive intake of beverages or energy drinks containing caffeine is relatively frequent. However, death due to caffeine intoxication is rare and case reports of fatalities from caffeine toxicity are relatively infrequent. In this report, we describe an autopsy case involving a 31 year-old man who intentionally took a large amount of caffeine tablets in the form of a weight loss supplement as part of a suicide plan. Caffeine femoral blood concentration $(170 \mathrm{mg} / \mathrm{l})$ was within the toxic and potentially lethal ranges reported in the literature in similar cases. Postmortem biochemistry results suggested depressed glomerular filtration rate and pre-renal failure at the time of death but failed to reveal myoglobinuria, glycosuria, ketonuria or ketonemia. Based on the absence of pathological findings at autopsy and the high blood caffeine level, death was attributed to acute caffeine toxicity. The case emphasizes the usefulness of performing exhaustive toxicology and searching for all potentially relevant information in order to
\end{abstract}

A. Bonsignore $\cdot$ S. Sblano $\cdot$ A. Dell'Erba

DIM - Section of Legal Medicine, University of Bari, Bari, Italy

A. Bonsignore $\cdot$ F. Ventura

Department of Legal Medicine, University of Genova, Genoa, Italy

F. Pozzi

Department of Public Health, Neurosciences, Experimental and Forensic Medicine, University of Pavia, Pavia, Italy

\section{Palmiere $(\square)$}

Centre Universitaire Romand de Médecine Légale, University Center of Legal Medicine, Rue du Bugnon 21, 1011 Lausanne, Switzerland

e-mail: cristian.palmiere@chuv.ch formulate appropriate hypotheses concerning the cause and manner of death.

Keywords Caffeine - Fatal intoxication - Toxicology · GC-MS · Postmortem biochemistry

\section{Introduction}

Caffeine (1,3,7-trimethylxanthine) is a natural xanthine alkaloid that acts as a central nervous system stimulant. Individuals may be exposed to caffeine via classical beverages (coffee, tea, chocolate, and most colas), food, prescription and over-the-counter medications, as well as herbal and dietary supplements. The molecule is one of the ingredients in health food products sold as appetite suppressants. Caffeine consumption has increased in recent years. This is especially true among young people, students, and athletes who also consume it in a more concentrated form as energy drinks, "energy shots" (smaller in volume as they lack the large amounts of sugars, carbohydrates, and/or carbonated water of classical energy drinks containing caffeine) or, of most concern, as $100 \%$ caffeine anhydrous, a high-dose self-administered drink additive [1-15].

Intentional or unintentional caffeine abuse due to excessive intake of beverages or energy drinks containing caffeine is relatively frequent and responsible for classical clinical manifestations of overstimulation. However, death due to caffeine intoxication is rare and case reports of fatalities from caffeine toxicity are relatively infrequent. In recent years, the risk of intentionally or unintentionally ingesting potentially lethal levels of caffeine has been heightened by its easy availability. Indeed, energy drinks and shots with high caffeine content are readily found in 
shops and health stores and pure caffeine anhydrous and anorecting tablets can be purchased online [16-22].

In this report, we described an autopsy case involving a 31 year-old-man who intentionally took a large amount of caffeine tablets in the form of a weight loss supplement as part of a suicide plan.

\section{Case history}

The body of a 31 year-old Caucasian man was found in his ex-girlfriend's apartment where he was staying although they had broken up. She had left the man alone in her apartment at 8:00 p.m. He did not indicate any problems to her at that time. He called her at 11:00 p.m. from the apartment, complaining of a sudden onset of bloody vomiting. Since he had previously used illness and physical symptoms as a pretext to gain her attention when she went out alone, the woman did not take this complaint seriously. When she returned at 4:00 a.m. she was unable to enter the apartment. She called the police after trying to contact the victim unsuccessfully by mobile phone several times. Upon arrival, police and first-aid workers found the door locked from the inside with the key still in the lock. The decedent was discovered in a bedroom. No blood or vomit was present around the body. A suicide note was found next him in which he purportedly mentioned that he was ending his life and wanted his ex-girlfriend to take care of his parents. No cardiopulmonary resuscitation attempts were performed and his death was pronounced at 5:25 a.m.

The body was found on the floor in a supine position, fully clothed. No tools or weapons were identified in the immediate vicinity of the body or in the other rooms of the apartment. No electrical appliances were switched on. No signs of drug use were discovered during the course of the inspection and no pills or tablets were found elsewhere in the apartment.

The deceased was $175 \mathrm{~cm}$ tall and weighed $65 \mathrm{~kg}$. External examination did not reveal anything remarkable. No bleeding wounds were observed at any site. The heart weighed $315 \mathrm{~g}$ and did not reveal any hypertrophy or dilatation. The myocardium did not exhibit fibrosis or ischemic areas, and the coronary arteries did not present morphological abnormalities. The lungs were relatively edematous and congested (left $600 \mathrm{~g}$, right $720 \mathrm{~g}$ ). The liver weighed $1,560 \mathrm{~g}$ and appeared yellowish brown, but no nodular lesions were found. The urinary bladder contained $50 \mathrm{ml}$ of cloudy yellow urine. The spleen $(120 \mathrm{~g})$ and kidneys (right $120 \mathrm{~g}$, left $130 \mathrm{~g}$ ) showed no significant macroscopic changes. The brain weighed $1,400 \mathrm{~g}$ and displayed edema with slight flattening of the gyri and mild cerebellar tonsillar grooving. The esophagus and the stomach contained an estimated $200 \mathrm{~g}$ of whitish-brownish material with identifiable fragments of undigested tablets.
Table 1 Postmortem biochemical investigation results

\begin{tabular}{|c|c|c|}
\hline Measured analyte & $\begin{array}{l}\text { Measured } \\
\text { concentration }\end{array}$ & $\begin{array}{l}\text { Clinical reference } \\
\text { value }\end{array}$ \\
\hline Postmortem serum urea & $\begin{array}{l}11.1 \mathrm{mmol} / \mathrm{l} \\
(31.09 \mathrm{mg} / \mathrm{dl})\end{array}$ & $\begin{array}{l}2.9-7.7 \mathrm{mmol} / \mathrm{l} \\
(8.1-21.6 \mathrm{mg} / \mathrm{dl})\end{array}$ \\
\hline $\begin{array}{l}\text { Postmortem serum } \\
\text { creatinine }\end{array}$ & $\begin{array}{l}126 \mu \mathrm{mol} / \mathrm{l} \\
(1.43 \mathrm{mg} / \mathrm{dl})\end{array}$ & $\begin{array}{l}62-106 \mu \mathrm{mol} / \mathrm{l} \\
(0.70-1.20 \mathrm{mg} / \mathrm{dl})\end{array}$ \\
\hline $\begin{array}{l}\text { Postmortem serum uric } \\
\text { acid }\end{array}$ & $\begin{array}{l}480 \mu \mathrm{mol} / \mathrm{l} \\
(8.07 \mathrm{mg} / \mathrm{dl})\end{array}$ & $\begin{array}{l}202-416 \mu \mathrm{mol} / \mathrm{l} \\
(3.40-7.00 \mathrm{mg} / \mathrm{dl})\end{array}$ \\
\hline $\begin{array}{l}\text { Postmortem serum beta- } \\
\text { tryptase }\end{array}$ & $9 \mathrm{ng} / \mathrm{ml}$ & $13 \mathrm{ng} / \mathrm{ml}$ \\
\hline $\begin{array}{l}\text { Blood beta- } \\
\text { hydroxybutyrate }\end{array}$ & $\begin{array}{l}126 \mu \mathrm{mol} / \mathrm{l} \\
(1.31 \mathrm{mg} / \mathrm{dl})\end{array}$ & $\begin{array}{l}50-170 \mu \mathrm{mol} / \mathrm{l} \\
(0.52-1.77 \mathrm{mg} / \mathrm{dl})\end{array}$ \\
\hline $\begin{array}{l}\text { Urine beta- } \\
\text { hydroxybutyrate }\end{array}$ & $\begin{array}{l}168 \mu \mathrm{mol} / \mathrm{l} \\
(1.75 \mathrm{mg} / \mathrm{dl})\end{array}$ & $\begin{array}{l}50-170 \mu \mathrm{mol} / 1 \\
(0.52-1.77 \mathrm{mg} / \mathrm{dl})\end{array}$ \\
\hline $\begin{array}{l}\text { Blood glycated } \\
\text { hemoglobin }\end{array}$ & $5.8 \%$ & $5.0-6.6 \%$ \\
\hline Urine myoglobin & n.d. & - \\
\hline Urine glucose & $\begin{array}{l}0.2 \mathrm{mmol} / \mathrm{l} \\
(3.6 \mathrm{mg} / \mathrm{dl})\end{array}$ & $\begin{array}{l}0.8 \mathrm{mmol} / \mathrm{l} \\
(14 \mathrm{mg} / \mathrm{dl})\end{array}$ \\
\hline Postmortem serum CDT & $2.2 \%$ & $1.6 \%$ \\
\hline $\begin{array}{l}\text { Postmortem serum } \\
\text { troponin I }\end{array}$ & $0.16 \mu \mathrm{g} / 1$ & $0.03 \mu \mathrm{g} / 1$ \\
\hline $\begin{array}{l}\text { Postmortem serum NT- } \\
\text { proBNP }\end{array}$ & $308 \mathrm{ng} / 1$ & $115 \mathrm{ng} / \mathrm{l}$ \\
\hline
\end{tabular}

$C D T$ carbohydrate-deficient transferrin, NT-proBNP N-terminal probrain natriuretic peptide, $n . d$. not detected

No other abnormalities were observed elsewhere in the body. Histological examinations revealed areas of fatty degeneration and focal fibrosis of the liver as well as slight acute renal tubule necrosis and hyalinized glomeruli in the kidneys. Acute generalized visceral congestion as well as cerebral and pulmonary edema was also noted.

Peripheral blood from the femoral vein, bile, urine, gastric content, and samples of certain tissues (brain, lung, liver, spleen, and kidney) were recovered for toxicological and biochemical analyses.

Biochemical investigations were performed in femoral blood and urine (Table 1). These included measurements of renal, hepatic, and cardiac function markers (in postmortem serum) as well as determination of beta-tryptase (in postmortem serum), beta-hydroxybutyrate (in blood and urine), glycated hemoglobin (in blood), myoglobin (in urine), glucose (in urine), and carbohydrate-deficient transferrin (CDT, in postmortem serum). The results were consistent with the presence of depressed glomerular filtration rate and pre-renal failure. Markers of cardiac function (N-terminal pro-brain natriuretic peptide and troponin I) and CDT levels were increased. Urine myoglobin, urine glucose, as well as beta-hydroxybutyrate in blood and urine, were not increased. 
Toxicology included carbon monoxide, cyanide, ethanol, and other volatile compound determination as well as general screening for nonvolatile drugs, poisons, and metabolites by gas chromatography-mass spectrometry (GC-MS) using commercial mass spectrum libraries, highperformance liquid chromatography with ultraviolet/diodearray detection (HPLC-UV-DAD) and headspace-gas chromatography (HS-GC) for volatile compound analysis.

Toxicological investigations performed on the blood samples revealed the presence of ethanol $(0.24 \mathrm{~g} / \mathrm{l})$, caffeine $(170 \mathrm{mg} / \mathrm{l})$, and acetylsalicylic acid $(169 \mathrm{mg} / \mathrm{l})$. Ethanol was measured in the blood using HS-GC-FID. Caffeine was quantified by HPLC-UV-DAD.

Analyses carried out in other samples and tissues to measure caffeine concentrations provided the following results: gastric content $10,204 \mathrm{mg} / \mathrm{ml}$, urine $79 \mathrm{mg} / \mathrm{l}$, bile $365 \mathrm{mg} / \mathrm{l}$, brain $544 \mathrm{mg} / \mathrm{l}$, lung $811 \mathrm{mg} / \mathrm{l}$, liver $556 \mathrm{mg} / \mathrm{l}$, spleen $824 \mathrm{mg} / \mathrm{l}$, kidney $1,755 \mathrm{mg} / \mathrm{l}$.

The measured concentration of caffeine in the gastric content $(10,204 \mathrm{mg} / \mathrm{ml})$ and the volume of the gastric content at autopsy $(200 \mathrm{~g})$ enabled investigators to estimate the amount of caffeine in the gastric content to be approximately $2 \mathrm{~g}$.

Based on the high blood caffeine level (in agreement with those reported in the literature in fatal cases due to caffeine poisoning) and the absence of pathological findings at autopsy, death was attributed to acute caffeine toxicity.

\section{Other investigations}

According to medical records that were obtained from relatives of the decedent, local health services and general practitioners, the man suffered from chronic alcohol abuse. A year prior to his death he had been hospitalized for attempted suicide using analgesic pills (ibuprofen).

After having received the toxicology results, pathologist and police investigators tried to obtain information from relatives and friends about the origin of the caffeine responsible for his death. The decedent's ex-girlfriend declared that, some weeks after the man's death, she found an empty vial that once contained 100 concentrated caffeine tablets ( $100 \mathrm{mg}$ pure caffeine/tablet) in his sport's bag. She had bought these pills 1 year prior to his death as an over-the-counter weight-loss supplement. However, she had rapidly stopped taking them as she had experienced significant adverse cardiac effects from them. She had completely forgotten about the tablets and was quite surprised to find the empty vial in his bag. She did not give any special meaning to this finding and did not announce it to the police. Indeed, she thought that he had taken these tablets over the months prior to his death to improve his sport performance. She did not have any suspicion that the drugs may have been involved in his death as she was convinced that he had died from alcohol and illicit substance intake.

\section{Discussion}

Death from caffeine poisoning, although rare, does occur. The direct cause of death is generally attributed to ventricular dysrhythmia, though caffeine cardiovascular effects are not limited to arrhythmogenesis $[5,11,18]$.

Caffeine is absorbed rapidly and completely when it is consumed orally. Clinical effects are identifiable within $15 \mathrm{~min}$ and peak plasma levels are attained within 15-45 min after ingestion. Caffeine undergoes hepatic metabolism via $\mathrm{N}$-demethylation, acetylation, and oxidation. The CYP450 1A2 isoenzyme is largely responsible for the $\mathrm{N}$-demethylation of caffeine to paraxanthine, its major metabolite. Chronic ingestion of alcohol and medications may prolong the half-life of caffeine by approximately $72 \%$, thus contributing to its toxic effects. Some fatalities might result from heightened and prolonged caffeine levels attributable to multiple drugs metabolized through the same metabolic pathway $[3,4,8,10,13]$.

Blood caffeine concentrations within $80-100 \mathrm{mg} / \mathrm{l}$ are generally considered lethal in humans, though correlations between blood levels and clinical effects are difficult to establish due to inter-individual variability, tolerance, and/ or pre-existing disease states. Fatalities among adults are reported following ingested doses of 5-50 g, even though recovery after ingestion of $30 \mathrm{~g}$ has been described. Ingestion over a brief time of 3-10 $\mathrm{g}$ of caffeine might be lethal $[2-4,8,10,13]$.

Cases of clinically significant toxicity in healthy adults have been described following the intake of a large number of energy drinks. However, to reach the dose of $3 \mathrm{~g}$ of ingested caffeine, a person would need to drink a large number of highly caffeinated beverages within a few hours $[4,5,8,10,13,17,20,21]$.

Fatalities following ingestion of huge amounts of pure anhydrous caffeine or caffeine pills have occasionally been described in the literature. The lethal concentration of $80-100 \mathrm{mg} / \mathrm{l}$ in blood can theoretically be reached after ingestion of 50-100 caffeine tablets containing $100 \mathrm{mg}$ of pure caffeine $[3,7]$.

In this case, the cause of death was attributed to fatal caffeine intoxication, with the manner of death designated as voluntary ingestion of several pure caffeine tablets. The exact amount of the ingested tablets could not been determined. Based on the decedent's ex-girlfriend's testimony, the vial should have contained at least 90 tablets, which, if they were all taken, would have resulted in ingesting a total amount of about $9 \mathrm{~g}$ of pure caffeine. This 
hypothesis is consistent with the aforementioned data provided by the literature, which indicates that fatal blood levels may be reached by ingesting 50-100 tablets of $100 \mathrm{mg}$ pure caffeine $[3,13]$.

Toxicological analyses of the femoral blood, urine, bile, and other tissue from the deceased confirmed that the active ingredient in the ingested tablets was caffeine. The femoral blood concentration $(170 \mathrm{mg} / \mathrm{l})$ was within the toxic and potentially lethal ranges reported in the literature in similar cases. Caffeine concentrations in the other biological samples tested were comparable to values found in caffeine fatalities in which the molecule was analyzed in numerous fluids and tissues collected during autopsy.

As acetylsalicylic acid is metabolized by uridine $5^{\prime}$ diphospho-glucuronosyltransferase $1 \mathrm{~A} 6$ and cytochrome P450 2C9, its concomitant presence in the blood (169 mg/ 1) does not seem to have played a role in modifying caffeine metabolism, prolonging its half-life or finally contributing to the toxic effects. Postmortem biochemistry results suggested that there was a depressed glomerular filtration rate and pre-renal failure at the time of death, likely following severe vomiting. Normal myoglobin, glucose, and beta-hydroxybutyrate levels in blood and urine suggested that the death occurred relatively rapidly after the caffeine ingestion, thus not allowing metabolic complications to take place.

\section{Key points}

1. Caffeine intoxications and suicides due to ingestion of tablets with high caffeine contents, do occur, albeit rarely.

2. The effects of caffeine after ingestion (or administration) are rapid and pharmacological interactions with other drugs exist which can potentially raise blood caffeine levels after concomitant intake.

3. High blood caffeine levels, though not lethal, should be considered as potentially being involved in the cause of death, especially in cases of pre-existing diseases or when drugs sharing the same metabolic pathway are concomitantly present.

4. The correlation of medical and social history, autopsy observations, histology findings, toxicological data and postmortem biochemical results are decisive in identifying the cause of death and characterizing the pathophysiological mechanisms involved in the death process.

\section{References}

1. Winek CL, Wahba W, Williams K, Blenko J, Janssen J. Caffeine fatality: a case report. Forensic Sci Int. 1985;29(3-4):207-11.

2. Riesselmann B, Rosenbaum F, Roscher S, Schneider V. Fatal caffeine intoxication. Forensic Sci Int. 1999;103:S49-52.

3. Holmgren O, Nordén-Pettersson L, Ahlner J. Caffeine fatalitiesfour case reports. Forensic Sci Int. 2004;139(1):71-3.

4. Kerrigan S, Lindsey T. Fatal caffeine overdose: two case reports. Forensic Sci Int. 2005;153(1):67-9.

5. Berger AJ, Alford K. Cardiac arrest in a young man following excess consumption of caffeinated "energy drinks". Med J Aust. 2009;190(1):41-3.

6. Rudolph T, Knudsen K. A case of fatal caffeine poisoning. Acta Anaesthesiol Scand. 2010;54(4):521-3.

7. Jabbar SB, Hanly MG. Fatal caffeine overdose: a case report and review of the literature. Am J Forensic Med Pathol. 2013;34(4):321-4.

8. Hoyte CO, Albert D, Heard KJ. The use of energy drinks, dietary supplement, and prescription medications by United States college students to enhance athletic performance. J Community Health. 2013;38(3):575-80.

9. Hoyte C. The toxicity of energy drinks: myth or reality? Clin Toxicol (Phila). 2013;51(8):729-30.

10. Sepkowitz KA. Energy drinks and caffeine-related adverse effects. JAMA. 2013;309(3):243-4.

11. Avc1 S, Sarıkaya R, Büyükcam F. Death of a young man after overuse of energy drink. Am J Emerg Med. 2013;31(11):1624.e3-4.

12. Wolk BJ, Ganetsky M, Babu M. Toxicity of energy drinks. Curr Opin Pediatr. 2012;24(2):243-51.

13. Thelander G, Jönsson AK, Personne M, Forsberg GS, Lundquist KM, Ahlner J. Caffeine fatalities-do sales restrictions prevent intentional intoxications? Clin Toxicol (Phila). 2010;48(4): 354-8.

14. Schubert MM, Astorino TA, Azevedo JL Jr. The effects of caffeinated "energy shots" on time trial performance. Nutrients. 2013;5(6):2062-75.

15. Bigard AX. Risks of energy drinks in youth. Arch Pediatr. 2010;17(11):1625-31.

16. McCarthy DM, Mycyk MB, DesLauriers CA. Hospitalization for caffeine abuse is associated with abuse of other pharmaceutical products. Am J Emerg Med. 2008;26(7):799-802.

17. Szpak A, Allen D. A case of acute suicidality following excessive caffeine intake. J Psychopharmacol. 2012;26(11):1502-10.

18. Poussel M, Kimmoun A, Levy B, Gambier N, Dudek F, Puskarczyk E, Poussel JF, Chenuel B. Fatal cardiac arrhythmia following voluntary caffeine overdose in an amateur body-builder athlete. Int J Cardiol. 2013;166(3):e41-2.

19. Emohare O, Ratnam V. Multiple cardiac arrests following an overdose of caffeine complicated by penetrating trauma. Anaesthesia. 2006;61(1):54-6.

20. Cannon ME, Cooke CT, McCarthy JS. Caffeine-induced cardiac arrhythmia: an unrecognized danger of healthfood products. Med J Aust. 2001;174(10):520-1.

21. Garriott JC, Simmons LM, Poklis A, Mackell MA. Five cases of fatal overdose from caffeine-containing "look-alike" drugs. J Anal Toxicol. 1985;9(3):141-3.

22. Kapur R, Smith MD. Treatment of cardiovascular collapse from caffeine overdose with lidocaine, phenylephrine, and hemodyalysis. Am J Emerg Med. 2009;27(2):253.e3-6. 